\title{
Development of the computerized decision- making support system for the prevention and revealing of dangerous zones of flooding
}

\author{
Farrukh Shaazizov ${ }^{1, *}$, Bakhtiyar Uralov ${ }^{1}$, Elyor Shukurov ${ }^{1}$ and Aydar Nasrulin ${ }^{2}$ \\ ${ }^{1}$ Tashkent institute of irrigation and agricultural mechanization engineers, Tashkent, Uzbekistan \\ ${ }^{2}$ Tashkent state technical university, Tashkent, Uzbekistan
}

\begin{abstract}
In considered article the results are presented of the carried out researches on high-mountainous lakes of the Tashkent area. Visual inspection of a modern condition of natural dams of considered highmountainous lakes of the Tashkent oblast is carried out. On the basis of the analysis of visual inspection it is possible to note, that the common technical condition of natural dams of the submitted high-mountainous lakes safe and does not represent danger to downstream situated territories. It was carried out the modeling of occurrence of emergency situation on high-mountainous lakes of the Tashkent oblast in case of full or partial destruction of natural dams. By an available calculation method of flooding waves are determined its key parameters, height of a wave, speed of distribution of a wave of break on the certain distances and reaching time the given wave up to the certain distances. On the basis of calculation method have been calculated and put on cross-sections of the rivers Pskem and Kocy zones of possible flooding in full and partial destruction of dams of high-mountainous lakes. Results of the carried out calculations have been put on the digital map, created on platform ArcView 3.2a.
\end{abstract}

\section{Introduction}

It is necessary to note, that at present is marked the most intensive development under building and cultivation of crops the coastal zones of the high-mountainous rivers which are subject to flooding in the case of breakout of situated in up streams on them of highmountainous lakes and water reservoirs.

Realization of the given research is aimed to development of the computerized decisionmaking support system for the prevention and revealing of dangerous zones of flooding, for the purposes of safe building coastal territories of valleys of the high-mountainous rivers and acceptance of the most effective architectural - planning decisions of settlements.

The given system is constructed on base GIS - technologies which allows to solve optimization task of definition of safe planned zones of buildings at various scripts of formation of breakout waves and scales of destruction both natural, and artificial dams,

\footnotetext{
*Corresponding author: shosfarruh@mail.ru
} 
situated on the top water objects and to choose the most effective architectural - planning decisions of settlements.

Developed by laboratory « Hydrology and hydraulic engineering » of the institute of Water problems the technique allows to determine zones of flooding on the basis of the advanced calculation model and to define zones of safe building of coastal zones of the highmountainous rivers and by that to choose the most effective architectural - planning decisions of settlements.

The basic purpose of the carried out researches is: Development of a calculation technique of breakout waves of water objects and the computerized decision-making support system for the prevention and revealing of dangerous zones of flooding, for the purposes of safe building coastal territories of valleys of the rivers.

For achievement of the main aim of our investigations there was a necessity to solve tasks which were reduced to the following:

- Creation of digital model of a relief on the basis of a cartographical material of topographical maps;

- Development and improvement of a calculation technique of breakout wave formed at destruction of the partitioning off dam at various scales of its destruction;

- Definition of a modern technical and safe condition of partitioning off dams of considered high-mountainous water objects.

- Carrying out of calculations by definition of key parameters of breakout wave formed as a result of break of natural dams of considered water objects;

- Definition of zones of flooding the bottom territories in passing of breakout wave;

- An estimation of a degree of danger and zones of risk and an estimation of possible damage of possible break of considered high-mountainous water objects proceeding from threats;

- Development and creation of the computerized decision-making support system to prevent and revealing of dangerous zones of flooding, for the purposes of safe building coastal territories of valleys of the rivers.

The analysis of the literature devoted to studying of safety issues of hydrotechnical constructions, in particular dams, shows that these constructions can at occurrence on them of failures lead to extreme situations in the big territories. The probability of failures increases at the big term of operation of constructions which term exceeds 30-40 years. The analysis of the failures which have occurred as a result of destruction of dams specifies on their rather high on the average reliability, however on each one thousand dams one large failure or failure with heavy consequences (human victims, the big material losses, ecological infringements, etc.) [1-10].

Besides in the nature there are some lakes formed as a result of blocking of great volume of mountain weight in the rivers. Natural dams as, for example, high-mountainous lake Sarez is formed as a result of displacement of the big mountain weight subsequently by a strong earthquake. High-mountainous lakes of such type, as a rule, are formed as a result of natural calamity (emergency situation) of natural character - strong earthquakes, landslide processes, mudstream phenomena.

To determine durability of existence of natural dams of high-mountainous lakes blocking a river beds represents the big difficulties in view of uncertainty of structure of mountain weight of a body of a natural dam. Such destructions of natural dams can cause large-scale destructions and formation of flooding waves which passing downstream of rivers and can overflow the big territories and result in human victims. Therefore for today one of the actual problems are calculation and definition of parameters of flooding waves, and 
definition of zones of flooding, with the purpose of definition of zones of paramount evacuation of the population from the settlements located in considered territories.

The mountain areas of the Tashkent oblast are account about ten dangerous highmountainous lakes. High-mountainous lakes concern to the largest lakes formed by obstruction such as Shavorkul, Big Ikhnach and Bottom Ikhnach and Koksu.

Besides it is necessary to note, that nowadays it is observed the intensive development under building and cultivation of crops of coastal zones of the high-mountainous rivers that are exposed of flooding by passage of freshet waters, and also by breaking down of highmountainous lakes and water reservoirs situated upstream.

Tasks of the given researches was definition of parameters of flooding wave formed as a result of breaking down of natural dams of the given lakes and definition of zones of flooding by passage of flooding wave with the purpose of definition of zones of paramount evacuation of the population from settlements, located in considered territories.

\section{Purposes and research tasks}

The main purpose of the carried out researches is:

Estimation of a degree of danger and zones of risk and estimation of possible damage of possible break of high-mountainous lakes Shavorkul, Big Ikhnach and Bottom Ikhnach and Koksu proceeding from threats, which are submitted in figure.

The object in view pursued the decision of the following tasks which are reduced to the following:

- Definition of modern technical and safe condition of partitioning off natural dams of high-mountainous lakes

- Definition of parameters of flooding wave formed as a result of break of natural dams of the given lakes

- Definition of zones of flooding in case of passage of a wave of break

For performance of the first research task has been organized expedition and flights and visual researches of the common technical condition of natural dams of high-mountainous lakes of the Tashkent oblast are carried out joint with services Uzgidromet and Ministry of Emergency Situations of the Republic of Uzbekistan. Together with it at the given stage of carrying out of researches have been specified the coordinates of arrangement of the specified high-mountainous lakes with the purpose of drawing the specified highmountainous lakes and their numbering on platform ArcView 3.2.a.

For carrying out of calculations and definition of the basic hydraulic parameters of flooding waves and definitions of zones of flooding at passage of the given wave have been collected a primary material which has been given from Uzgidromet, and cartographical center "Uzgeodezkadastr".

From "Uzgidromet"

- Maps - circuit of bathiometric mesures of high-mountainous lakes Shavorkul, Big Ikhnach and Bottom Ikhnach and Koksu;

- The maximal volumes of lakes;

- Lengths of run flooding waves from the set forth above lakes up to characteristic objects.

From "Uzgeodezkadastr":

- Topographical maps in scales of M 1:100 000; M 1:50 000; M 1:25 000.

For definition of key parameters of flooding waves which can be formed as a result of break of natural dams of high-mountainous lakes of Tashkent oblast Shavorkul, Big Ikhnach and Bottom Ikhnach and Koksu on the rivers have been planned settlement ranges.

On the river Pskem which formed from Shavorkul lake it planned 12 settlement ranges. 
On the river Ikhnachsay which formed from Big Ikhnach and Bottom Ikhnach lakes it planned 3 settlement ranges.

On the river Koksu which formed from Koksu lake it planned 5 settlement ranges.

For carrying out of a tentative estimation of zones of flooding and revealing of dangerous zones of flooding, for the purposes of safe building coastal territories of valleys of the rivers it has been used the method of approached calculation of key parameters flooding waves.

\section{Results}

\section{Definition of time of arrival of water on the set distances}

According to the mentioned below formula it was determined the time of arrival of flooding wave for the set distances.

$$
t=\frac{R}{V}
$$

Where: R- the set distance from a dam set in kilometers;

$\mathrm{V}$ - average speed of movement of flooding wave.

\section{Definition of height of flooding wave on the certain distances}

In the given approached calculation method have been used the empirical graphic dependences revealed earlier as a result of carried out experimental researches in laboratory conditions for definition of height of flooding wave on various distances downstream after a dam (fig. 1) .

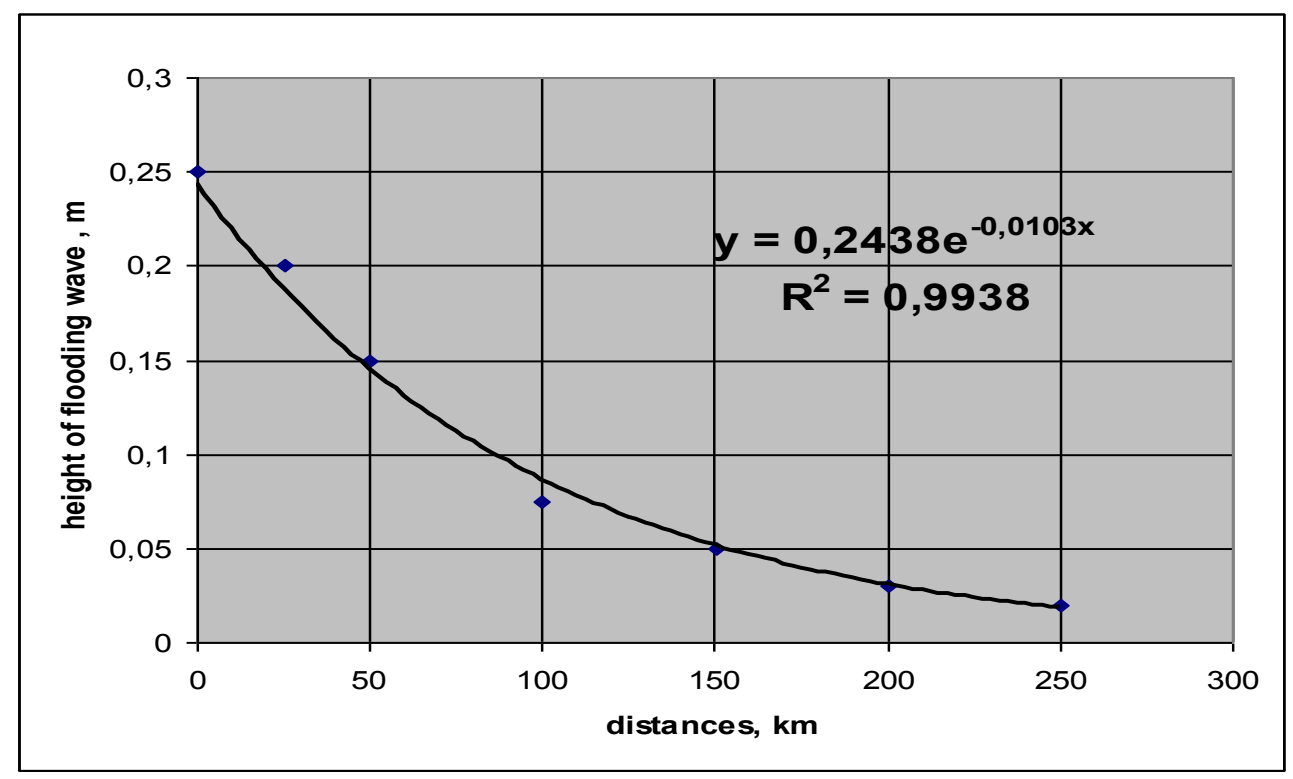

Fig. 1. Height of flooding wave on various distances from a dam 


\section{Definition of duration of passage of flooding wave on the set distances}

Duration of passage of flooding wave on the set distances was determined under the following formula:

$$
T=\frac{W}{Q \times V_{B} \times 3600}
$$

Where: $\mathrm{W}$ - volume of a water reservoir, $\mathrm{m}^{3}$;

$\mathrm{V}_{\mathrm{B}}$ - average speed of movement of flooding wave.

$\mathrm{Q}$ - the maximal discharge of water on $1 \mathrm{M}$ running width a prowound which is determined under table 1 .

Table 1. Definition of water discharge depending on width a prowound and an available pressure in a reservoir

\begin{tabular}{|l|c|c|c|c|}
\hline $\mathrm{H}, \mathrm{m}$ & 5 & 10 & 25 & 50 \\
\hline $\begin{array}{l}\text { Q, } \mathrm{m}^{3} / \mathrm{s} \text { per } 1 \mathrm{~m} \\
\text { width }\end{array}$ & 10 & 30 & 125 & 350 \\
\hline
\end{tabular}

For concrete conditions, i.e. for two scripts of a possible origin of an extreme situation (at full destruction of a natural dam and at destruction of a dam on half) parameters of flooding waves on each of the planned sections for full and partial destruction of a dam accordingly (a level of waters have been determined.

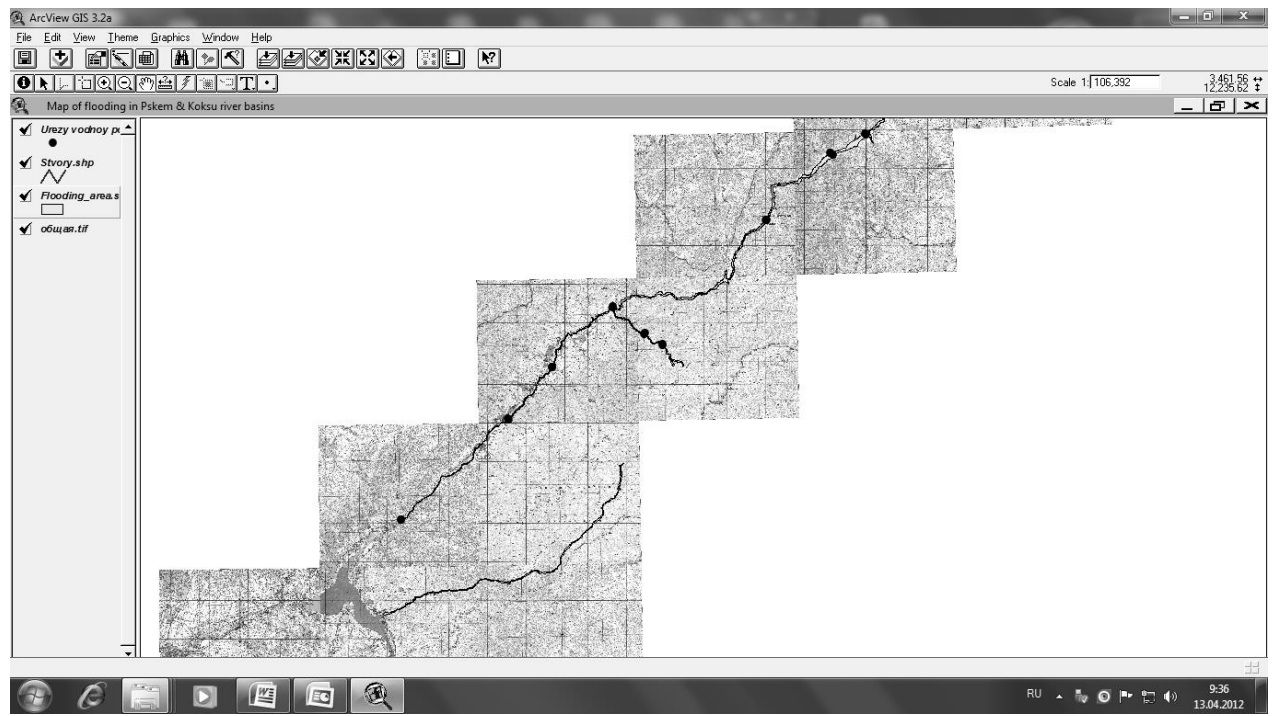

Fig. 2. The computerized system of support of decision-making under the prevention and revealing of dangerous zones of flooding on the rivers Pskem and Koksu on platform ArcView 3.2.a

On the basis of use of GIS technologies numbering of map have been made and scales and consequences of passage flooding waves are determined and zones are determined of flooding in territory of the Tashkent area up to Charvak water reservoir. 
Results of the carried out researches show, that the maximal wave of break forming at full destruction of natural dams of lakes Shavorkul, Big Ikhnach and Bottom Ikhnach in range at an entrance to Charvak water reservoir makes 7.5 meters. Minimal and really possible reach time of flooding waves up to given range on the river Pskem takes 1,058 hour.

On the river results of researches show Koksu, that the maximal wave of break forming at full destruction of a natural dam of lake Koksu in range at entrance in Charvak water reservoir makes 16.6 meters. Minimal and really possible reaching time of flooding waves up to given range on the river Koksu takes 0,3125 hour.

It is necessary to note, that all considered high-mountainous rivers proceed in deep and narrow gorges and height of flooding waves, formed at break of high-mountainous lakes, do not represent special danger to the locations of the given rivers, except for places of injection of the rivers Pskem and Koksu in Charvak water reservoir where located settlements.

\section{Conclusions}

- Visual inspection of a modern condition of natural dams of considered highmountainous lakes of the Tashkent oblast is carried out.

- On the basis of the analysis of visual inspection it is possible to note, that the common technical condition of natural dams of the submitted high-mountainous lakes safe and does not represent danger to down stream situated territories.

- It was carried out the modeling of occurrence of emergency situation on highmountainous lakes of the Tashkent oblast in case of full or partial destruction of natural dams.

- On the basis of a topographical material have been made cross-section sections of Pskem and Koksu river beds.

- By an available calculation method of flooding waves are determined its key parameters, height of a wave, speed of distribution of a wave of break on the certain distances and reaching time the given wave up to the certain distances.

- On the basis of calculation method have been calculated and put on cross-sections of the rivers Pskem and Kocy zones of possible flooding in full and partial destruction of dams of high-mountainous lakes.

\section{References}

1. V.I. Pcholkin Safety of buildings and constructions in a zone of hydrodynamical failures on hydraulic engineering constructions J. Techn. of Civ. safety VNII GOCHS 2, 4 pp.66-69. (2004)

2. Shangareev $S$ Engineering protection of hydraulic engineering constructions J. Civ. Prot. 5 pp. 25-26. (2003)

3. Shaazizov F Sh Experience of use of GIS-technologies by development of criteria of safe operation especially large Republics Uzbekistan, Coll. of artic. SANIIRI Land improvement and a water management, pp. 174-178. (2006)

4. Shaazizov F Sh Computer supported system for the risk assessment and action recommendation for the water objects in Uzbekistan based on the databank already developed, Coll. of artic. Biosaline agriculture and high salinity tolerance, pp. 71-72. (2006)

5. Shaazizov F Sh Assessment of the risk of a breakthrough in the highland lakes of the Tashkent region LAP Lambert Academic Publishing OmniScriptum GmbH\&Co.KG Saarbrucken Deutschland, p.193. (2015) 
6. Shaazizov F Sh Assessment and management of natural risks in the Tashkent region, Coll. of artic. Modern problems of hydrogeology, engineering geology, geoecology and ways to solve them by the State Committee on Geology of the Republic of Uzbekistan, pp. 209-211. (2015)

7. Shaazizov F Sh Application of GIS technologies in modeling the emergence of natural emergencies in the Tashkent region of the Republic of Uzbekistan, Coll. of artic. Tyumen Industrial University, Tyumen, pp. 297-303. (2017)

8. Shaazizov F Sh To the issue of modeling the breakthrough of high-mountain lakes in the Tashkent region, Coll. of artic. Analysis, forecast and management of natural risks taking into account global climate change GEORISK - 2018, 1 Moscow, pp. 413418. (2018)

9. Shaazizov F Sh On the development of a decision support system for the prevention and detection of hazardous areas of flooding, Coll. of artic. GEORISK-2012, Moscow, pp.197-202. (2012)

10. Shaazizov F Sh Some aspects to the issue of developing a decision support system for the prevention and detection of hazardous areas of flooding, Coll. of artic. Kostyakov's readings, Moscow pp.435-439. (2013) 